1. MBBS (Pb), FCPS

Assistant Professor Medical Unit 3

FJMU, SGRH, Lahore.

2. MBBS $(\mathrm{Pb}), \mathrm{MPH}$, M.Phil

Assistant Professor

Institute of Public Health, Lahore.

3. Bsc MLT

Student

4. MBBS (Pb), MPH, M.Phil

Assistant Professor

Institute of Public Health, Lahore.

5. BSc. (Pb), MBBS

FJMU.

6. MBBS (KEMC), MD (USA), DABIM (USA),

DABGM (USA), FACP (USA)

Assistant Professor

Indiana University, School of Medicine. IN, USA.

7. MBBS (KEMC), DHA (Pb), MSc. (UK)

Member of Faulty \& Ex-Chair Family \& Community Medicine

King Faisal University, Saudi Arabia.

Correspondence Address:

Dr. Saima Ayub

Department of Bacteriology

Institute of Public Health,

6 Birdwood Road, Lahore.

drsaimaayub@yahoo.com

Article received on:

25/06/2019

Accepted for publication:

$13 / 01 / 2020$

\section{FREQUENCY OF METHICILLIN RESISTANT STAPHYLOCOCCUS AUREUS IN A TERTIARY CARE (SERVICES HOSPITAL) LAHORE.}

Khadija Muneer ${ }^{1}$, Saima Ayub ${ }^{2}$, Jazab Aqeel ${ }^{3}$, Surraya Jaffer ${ }^{4}$, Taimia Ayub ${ }^{5}$, Saim Maqsood ${ }^{6}$, Ayub Ali

ABSTRACT: Staphylococcus aureus is a gram positive coccus responsible for severe morbidity and mortality as it causes community and hospital acquired infections. The Methicillin resistant Staphylococcus aureus is responsible for several difficult to treat infections in human. Objectives: To find out Frequency of Methicillin resistant Staphylococcus aureus in Patients in a tertiary care hospital of Lahore. Study Design: Cross-sectional study. Setting: Tertiary care (Services Hospital) Lahore. Period: Four months from $1^{\text {st }}$ August 2017 to $30^{\text {th }}$ November 2017. Material \& Methods: A total of 2534 isolates were obtained during the period (1 August 2017 to 30 November 2017) from patients at a tertiary care hospital of Lahore. Specimen were inoculated on blood agar plates, strains obtained were confirmed for Staphylococcus aureus using conventional biochemical tests and oxacillin disk test was performed to confirm methicillin resistant Staphylococcus aureus. Result: Out of 104 Staphylococcus aureus isolates, methicillin resistant Staphylococcus aureus was 46 (44.2\%) and methicillin sensitive Staphylococcus aureus was 58 (55.8\%). Conclusion: Methicillin resistant Staphylococcus aureus is a big challenge for current health care system and this may be a cause of morbidity and mortality in community and hospital patients.

Key words: $\quad$ MRSA, Methicillin, Oxacillin, Staphylococcus Aureus.

Article Citation: Muneer K, Ayub S, Aqeel J, Jaffer S, Ayub T, Maqsood S, Ali A. Frequency of methicillin resistant staphylococcus aureus in a Tertiary care (Services Hospital) Lahore. Professional Med J 2020; $27(3): 576-580$.

DOI: 10.29309/TPMJ/2020.27.3.3678

\section{INTRODUCTION}

A large number of treatment resistant human infections are caused by methicillin resistant staphylococcus aureus (MRSA) which is also called oxacillin resistant staphylococcus aureus (ORSA). It was first discovered in hospitals and health centers where it flourished due to favorable conditions such as immunocompromised patients and excessive usage of antibiotics. MRSA has been commonly implicated in infections of CVP catheters, hospital/ventilator acquired pneumonia and post-surgical wound complications. ${ }^{1}$ Its resistance to commonly used antibiotics makes it a particularly troublesome microbe to treat. ${ }^{2}$ MRSA carries the mecA gene ${ }^{3}$ which interferes with the $\beta$-lactam component of penicillins reducing their potency. Patients with decreased immunity (e.g. diabetics, AIDS, transplant recipients, extremes of age) $)^{4,5,6}$ are considered to be at-risk. Other atrisk groups include areas of increased population density, females with recurrent UTI, working staff at hospitals and people who frequently share equipment. MRSA infection rates have steadily been rising over the recent years compounded by the increased usage of penicillins and the subsequent development of resistance. In late 1960 , more than $80 \%$ of S. aureus cultures taken from various communities and hospitals showed penicillin resistance. ${ }^{7}$ Community associated MRSA, observed throughout the world, has often been seen to show sensitivity to other antiobiotic groups e.g. sulfonamides. ${ }^{8}$

In 2000 in the USA, MRSA was implicated as the cause of skin infections in Missouri and Pennsylvania affecting prisoners and football player's respectively. ${ }^{9}$ The particular strain, USA300, soon became prominent in $\mathrm{USA}^{10}$ as it caused widespread infections, being detected in 11 emergency centers, military installations, Native American groups, prisons and daycare centers. It has also been isolated from cases 
of necrotizing pneumonia, osteomyelitis and septicemia. USA300 strain exhibits resistance to drugs like fluoroquinolones and tetracycline's and has been identified in other regions like Australia and Europe. Its prevalence has been rising and can often be found in up to $50 \%$ of S. aureus isolates in various hospitals. ${ }^{12}$ Effective measures to combat this organism are becoming more and more imperative. Judicious use of antibiotics is necessary as is research into mechanism of resistance to develop appropriate countermeasures. Newer drugs, better hygiene control, patient isolation are other avenues through which MRSA can be controlled. ${ }^{13}$

\section{OBJECTIVES}

- To find out the frequency of Methicillin Resistant Staphylococcus aureus (MRSA) from specimens (Blood, Urine, Pus and Fluid) in a tertiary care Hospital in Lahore.

- To give recommendation to decrease the incidence of nosocomial infection in the hospital.

\section{MATERIALS AND METHODS}

It was a cross-sectional study. Study was carried out in a tertiary care hospital of Lahore. Four months from $1^{\text {st }}$ August 2017 to $30^{\text {th }}$ November 2017. All the samples 2534 with in the above time period. Convenient sampling technique was used. A pre designed Performa was used to collect the data.

Using SPSS v.23 the data was managed and analyzed. Where as categorical variable was expressed in the form of frequency table and percentage, appropriate graphs were used to display the data.

Necessary permission was taken from the concerned authority. Confidentiality / privacy of the individual was maintain. The data was only to be used for academics and for policy making purposes.

\section{RESULTS}

\section{Frequency of Total Bacterial Growth}

Total of $\mathrm{N}=2534$ isolates were obtained from patients. Out of which 679 (26.8\%) show bacterial growth on culture media while 1855 (73.2\%) dose not shows any growth. Table-I

\begin{tabular}{|l|c|c|}
\hline & Frequency & Percent (\%) \\
\hline Growth & 679 & $26.8 \%$ \\
\hline No growth & 1855 & $73.2 \%$ \\
\hline Total & 2534 & $100.0 \%$ \\
\hline \multicolumn{2}{|c|}{ Table-l. Total bacterial growth $\mathbf{n = 2 5 3 4}$} \\
\hline
\end{tabular}

\section{Frequency of Staphylococcus Aureus Growth}

Total bacterial growth $n=679$ isolates, Staphylococcus aureus confirm growth 104 (15.3\%) and other type of bacterial growth is 575 (84.7\%) e.g. (Acinetobacter, Pseudomonas, Escherichia coli, Klebsiella, Candida, Morganella, Proteus and Citrobacter.) as shown in Table-II.

\begin{tabular}{|l|c|c|}
\hline & Frequency & Percent (\%) \\
\hline Staphylococcus aureus & 104 & $15.3 \%$ \\
\hline Other types of bacteria & 575 & $84.7 \%$ \\
\hline Total & 679 & $100.0 \%$ \\
\hline \multicolumn{2}{|c|}{ Table-II. Frequency of staphylococcus aureus growth } \\
$\mathbf{n = 6 7 9}$
\end{tabular}

\section{Frequency of MRSA}

Table-III shows confirm Staphylococcus aureus $\mathrm{n}=104$.

Out of 104, Methicillin resistant staphylococcus aureus is $46(44.2 \%)$ and methicillin sensitive Staphylococcus aureus is $58(55.8 \%)$.

\begin{tabular}{|c|c|c|}
\hline & Frequency & Percent (\%) \\
\hline MRSA & 46 & $44.2 \%$ \\
\hline MSSA & 58 & $55.8 \%$ \\
\hline Total & 104 & $100.0 \%$ \\
\hline Table-III. Frequency of MRSA $\mathbf{n = 1 0 4}$ \\
\hline
\end{tabular}

Figure Showing Frequency of MRSA Positive Out of $n=104$, methicillin resistant Staphylococcus aureus is $46(44.2 \%)$ and methicillin sensitive Staphylococcus aureus is 58 (55.8\%) as shown in Figure-1. 
Frequency of MRSA Positive

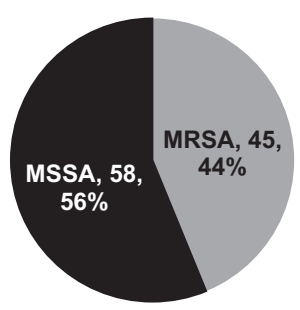

MRSA

Figure-1. Showing frequency of MRSA positive isolates.

\section{DISCUSSION}

MRSA infections are mostly acquired by patients in healthcare facilities such as hospitals, dialysis centers and nursing homes. These infections are known as healthcare associated MRSA (HA-MRSA) and are frequently responsible for complications of surgeries, joint replacements and long dwelling intravenous catheters. ${ }^{14}$

Another MRSA type is observed in the healthy community which is transmitted via skin contact, usually appearing as boils. This particularly involves groups such as individuals living in crowded places, child care centers, high school wrestlers etc. ${ }^{14}$ MRSA is also chronically carried by $2 \%$ of the population, as noted by the Centers for Disease Control and Prevention. ${ }^{15}$

MRSA is a particularly troublesome threat and serious challenge that needs to be overcome. It is among the most frequent causes of septicemia in wounds and burns and is chiefly transmitted by contaminated hands of clinical staff and/or touching the affected area directly. In addition, as many as one third of the population are silent carriers of MRSA in their nose, showing no observable symptoms and act as disease vectors. ${ }^{5}$

The aim of this study was to determine the frequency of patients in a tertiary care hospital who are infected by MRSA. $44.2 \%$ infections acquired in the hospital were attributable to MRSA which is comparable to another study done in India where 237 isolates of S. aureus were seen in a tertiary care hospital in Bangalore.
The prevalence of MRSA was $42 \%$ and $43 \%$ in wards and ICU respectively. MRSA also exhibited greater resistance to multiple drugs compared to methicillin sensitive staphylococcus aureus (MSSA). ${ }^{16}$

Higher prevalence of MRSA was seen in a study in Libya which involved $56-58 \%$ patients in burn and surgical units. ${ }^{17}$

A large number of difficult to treat hospital acquired infections are caused by MRSA and MSSA $^{18}$ and the number of cases of MRSA has been rising in the past decade globally. ${ }^{19}$ The rising prevalence is worrisome as it indicates the possibility of new virulent characteristics due to adaptability.

In Malaysia, a significant rise in MRSA prevalence has been noted in various hospitals since 1970.20 $60 \%$ cases of MRSA in Peshawar, Pakistan were acquired in hospitals especially in burn units and plastic surgery wards. Around 1.2 million admitted people each year were infected by MRSA. ${ }^{21}$

The infection rate of MRSA varies wildly between populations. In the Asia-Pacific region, Philippines showed a $5 \%$ MRSA infection rate while it was $79.5 \%$ in Hong Kong. The latter is much greater than the values obtained from USA (34.2\%), Europe (26.3\%), Canada (5.7\%) and Latin America $(34.9 \%) .^{22}$ The variations could be attributed to differences in the studied groups themselves as well as the methodology and techniques being used.

In South Africa, 772 out of 9971 patients (7.7\%) had S. aureus infections. ${ }^{23}$ In Eastern Uttar Pradesh, 301 out of 549 strains $(54.8 \%)$ of S. aureus were MRSA in a tertiary hospital. ${ }^{24}$ In our study, 104 out of 679 (15\%) specimens yielded S. aureus.

MRSA frequency is generally lower in European countries, likely due to stricter policies regarding antibiotic prescription and control of infections. As an example, Netherlands showed less than $1 \%$ isolates of $\mathrm{S}$. aureus with methicillin resistance. 


\section{CONCLUSION}

From this study it is concluded that, the prevalence of methicillin resistant Staphylococcus aureus (MRSA) is increases among clinical isolates of Staphylococcus aureus. Out of a total of $n=104$, MRSA positive strains isolated from random sample $n=46$ (44.2\%). All MRSA were resistant to penicillin. Active screening and compliance with recommended infection control practices play an important role in the control of MRSA.

\section{RECOMMENDATIONS}

1. Attention should be paid to stop the transmission of MRSA by health care workers by very careful hand washing. The hospital infection control policy and guidelines that already exists should be strictly followed so as to enable the clinicians to deliver better and proper health care to the patients.

2. Training of Health Care Worker (H.C.W).

3. Proper use of Antibiotic medication.

Copyright $@ 13$ Jan, 2020.

\section{REFRENCES}

1. Jevons MP. "Celbenin" - resistant Staphylococci. BMJ [Internet]. 1961 Jan 14; 1(5219):124-5. Available from: http://dx.doi.org/10.1136/bmj.1.5219.124-a.

2. Noorani HZ, Adams E, Glick S, Weber S, Belinson $S$, Aronson N. Screening for methicillin-resistant staphylococcus aureus (MRSA): Future research needs: Identification of future research needs from comparative effectiveness review No. 102 [Internet]. Available from: https://www.ncbi.nlm.nih.gov/books/ NBK154523/.

3. Wielders CLC, Fluit AC, Brisse S, Verhoef J, Schmitz FJ. Mec A. Gene is widely disseminated in staphylococcus aureus population. J Clin Microbiol. 2002 Nov 1; 40(11):3970-5.

4. Zervou FN, Zacharioudakis IM, Ziakas PD, Rich JD, Mylonakis E. Prevalence of and risk factors for methicillin-resistant staphylococcus aureus colonization in HIV infection: A meta-analysis. Clin Infect Dis. 2014 Nov 1; 59(9):1302-11.

5. Zacharioudakis IM; Zervou FN; Ziakas PD; Mylonakis E. Meta-analysis of methicillin-resistant Staphylococcus aureus colonization and risk of infection in dialysis patients. J Am Soc Nephrol. 2014; 25(9):2131-41.
6. Zervou FN, Zacharioudakis IM, Ziakas PD, Mylonakis E. MRSA colonization and risk of infection in the neonatal and pediatric ICU: A meta-analysis. Pediatrics. 2014 Mar 10; 133(4):e1015-23.

7. Klein E, Smith DL, Laxminarayan R. Hospitalizations and deaths caused by methicillin-resistant staphylococcus aureus, United States, 1999-2005. Emerg Infect Dis. 2007 Dec; 13(12):1840-6.

8. Ruhe JJ, Smith N, Bradsher RW, Menon A. Communityonset methicillin-resistant staphylococcus aureus Skin and Soft-Tissue Infections: Impact of Antimicrobial Therapy on Outcome. Clin Infect Dis. 2007 Mar 15; 44(6):777-84.

9. Carrel M, Perencevich EN, David MZ. USA300 Methicillin-Resistant Staphylococcus aureus, United States, 2000-2013. Emerg Infect Dis. 2015 Nov; 21(11):1973-80.

10. David MZ, Daum RS. Community-Associated Methicillin-Resistant Staphylococcus aureus: Epidemiology and clinical consequences of an emerging epidemic. Clin Microbiol Rev. 2010 Jul 1; 23(3):616-87.

11. Tenover FC, Goering RV. Methicillin-resistant staphylococcus aureus strain USA300: origin and epidemiology. J Antimicrob Chemother. 2009 Jul 16; 64(3):441-6.

12. Voss A, Doebbeling BN. The worldwide prevalence of methicillin-resistant Staphylococcus aureus. Int J Antimicrob Agents. 1995 Apr; 5(2):101-6.

13. Ledell K, Muto CA, Jarvis WR, Farr BM. SHEA guideline for preventing nosocomial transmission of multidrugresistant strains of staphylococcus aureus and enterococcus. Infect Control Hosp Epidemiol. 2003 Sep; 24(9):639-41.

14. MRSA infection Mayo clinic. https://wwwmayo clinic .org. mrsa. cited on march 2019.

15. MRSA CDC. https;//www.cdc.org.mrsa. cited on march 2019.

16. Pai V, Rao VI, Rao SP. Prevalence and antimicrobial susceptibility pattern of methicillin-resistant Staphylococcus aureus [MRSA] isolates at a tertiary care hospital in Mangalore, South India. Journal of laboratory physicians. 2010 Jul;2(2):82.

17. Buzaid, N. Ibrahim, T. Methicillin resistant Staphylococcus aureus (MRSA) in a Tertiary Surgical and Trauma Hospital in Benghazi, Libya. 2011 Microbiology, 723 - 726. 
18. Al-Talib $H$, Yean CY, Al-Khateeb A, Hassan $H$, Singh $\mathrm{KK}$, Al-Jashamy $\mathrm{K}$, et al. A pentaplex PCR assay for the rapid detection of methicillin-resistant staphylococcus aureus and Panton-Valentine Leucocidin. BMC Microbiol. 2009; 9: 113. [PMC free article] [PubMed].

19. Kluytmans-Vandenbergh Community-acquired MF, Kluytmans JA. methicillin-resistant staphylococcus aureus: Current perspectives. Clin Microbiol Infect. 2006; 12:9-15. [PubMed]

20. Cheong I, Tan SC, Wong YH, Zainudin BM, Rahman MZ. Methicillin-resistant Staphylococcus aureus (mrsa) in a Malaysian Hospital. Med J Malaysia. 1994; 49:248. [PubMed].

21. Asad ullah, Mohammad Qasim, hazir rehman. jafar khan etall. High frequency of methicillin resistant staphylococcus aureus in Peshawar Region of Pakistan. Springerplus.2016; 5; 600.
22. Bell JM, Turnidge JD; SENTRY APAC. High prevalence of oxacillin-resistant staphylococcus aureus isolates from hospitalized patients in Asia-Pacific and South Africa: results from SENTRY antimicrobial surveillance program, 1998-1999. Antimicrob Agents Chemother. 2002; 46:879-81. [PMC free article] [PubMed].

23. Liliwe L Shuping, Lazarus kuonza. Alfred Musikiwa, Smantha lyaloo, Olga Perovic. Hospital- associated methicillin-resistant Staphylococcus aureus; A cross sectional analysis of risk factor in South African tertiary public hospitals. PloS ONE 12 (11); e0188216 .https//doi.org/10.137/joumal.

24. Anupurba $S$ et al. Prevalence of methicillin resistant staphylococcus aureus in a Tertiary Referral Hospital in Eastern Uttar PRADESH. Indian J Med Microbial 2003 Jan-Mar.

25. Gebhardt DO. MRSA in Netherland; Preventive measure raises a moral issue. J Med Ethics. 2003; Aug: 29 (4):212.

\begin{tabular}{|c|c|c|c|}
\hline \multicolumn{4}{|c|}{ AUTHORSHIP AND CONTRIBUTION DECLARATION } \\
\hline Sr. \# & Author(s) Full Name & Contribution to the paper & Author(s) Signature \\
\hline 1 & Khadija Muneer & Write up. & Klowdig poun \\
\hline 2 & Saima Ayub & Write up. & Saimo Ayab. \\
\hline 3 & Jazab Aqeel & Data collection. & Iazab Aquel \\
\hline 4 & Surraya Jaffer & Data analysis. & Sirns. \\
\hline 5 & Taimia Ayub & Data collection. & \\
\hline 6 & Saim Maqsood & Data analysis. & \\
\hline 7 & Ayub Ali & Write up, Editing. & Ayob Ali \\
\hline
\end{tabular}

